\title{
Reflectie van eerstejaars studenten geneeskunde: wat willen we zien en wat doen de studenten?
}

\author{
S. Vink, H.J.M. Cools, G.M.F. Elsen, J.D. Vermunt
}

\section{Samenvatting}

Inleiding: In de eerstejaars stage in het Leidse curriculum worden studenten aangezet tot reflectie door een portfolio bij te houden. Onderzocht is welke soorten reflectie wenselijk zijn, welke soorten reflectie studenten hanteren en op welke domeinen van professioneel gedrag gereflecteerd wordt. Tevens is gekeken of beoordelaars de soorten reflectie en de domeinen van professioneel gedrag herkennen in de reflecties van studenten.

Methode: Op basis van de literatuur over reflectie en twintig portfolio's is een lijst van wenselijke soorten reflectie in de vorm van reflectieactiviteiten en domeinen van professioneel gedrag opgesteld. Twee onderzoekers hebben vervolgens de reflecties in 108 reflectieopdrachten gecategoriseerd op basis van deze lijst. Er zijn frequentietellingen gedaan en er is beoordelaarsovereenstemming berekend middels Cohens kappa.

Resultaten: Van de vijf reflectieactiviteiten (selecteren en beschrijven, evalueren, analyseren, plannen en generaliseren) blijken analyseren en generaliseren het minst voor te komen en het slechtst door de onderzoekers herkend te worden. Plannen en selecteren/beschrijven blijken vaak voor te komen en goed te kunnen worden onderscheiden. Evalueren is moeilijker te herkennen, maar komt vaak voor. De drie domeinen van professioneel gedrag blijken door de onderzoekers slechts zeer moeizaam te worden herkend. Studenten reflecteren wel op de drie verschillende domeinen.

Conclusies en discussie: Wenselijke soorten reflectie zijn goed te beschrijven in termen van leer- of reflectieactiviteiten. Helaas komen de gewenste reflectieactiviteiten niet allemaal in de gewenste mate voor in de portfolioverslagen van de eerstejaars studenten. Een verklaring daarvoor kan zijn dat studenten niet voldoende op deze reflectieactiviteiten worden aangestuurd. Meer sturing is dus gewenst als wij willen dat studenten een breed scala aan reflectieactiviteiten laten zien. Anderzijds laten studenten ook spontaan reflectie zien zonder dat zij daar expliciet op worden aangestuurd. Dit geldt voor evalueren. Er zijn liefst drie reflectieactiviteiten waar de beoordelaarsovereenstemming (zeer) tegenviel. Voorts blijkt het bij de beoordeling van portfolioverslagen lastig te zijn om een onderscheid naar domein te maken. Deze domeinen van professioneel gedrag lijken daarvoor te zeer vervlochten.

Reflectie is dikwijls een belangrijk element bij portfoliobeoordelingen. De resultaten van deze studie laten echter zien dat de betrouwbaarheid van beoordelingen van reflectie dient te worden verbeterd. (Vink S, Cools HJM, Elsen GMF, Vermunt JD. Reflectie van eerstejaars studenten geneeskunde: wat willen we zien en wat doen de studenten? Tijdschrift voor Medisch Onderwijs 2005;24(1):4-13.)

\section{Inleiding}

In het eerste studiejaar lopen de Leidse studenten geneeskunde een zorgstage in een verpleeghuis om hun professionele gedrag te ontwikkelen. Doel is dat de stu- denten zich bewust worden van hoe zij met taken, anderen en zichzelf omgaan. ${ }^{1-2}$ Door middel van een portfolio reflecteren zij op deze drie domeinen van professioneel gedrag. 
Het portfolio is gestructureerd rond de verschillende taken die de student moet uitvoeren. Zo is er een portfolio-opdracht rond de zorgtaak 'wassen, kleden, uiterlijk verzorgen', een opdracht rond de zorgtaak 'verplaatsen en toiletbezoek', de zorgtaak 'medicijnen en eten geven' en moet er twee keer een verslag worden geschreven naar aanleiding van de taak 'een professioneel gesprek (met een patiënt) voeren'. Figuur 1 toont hoe het portfolio bij de taak 'zich verplaatsen en toiletbezoek' eruit ziet. De overige taken zijn op identieke wijze gestructureerd. Merk op dat de studenten expliciet worden uitgenodigd om op hun gevoel te reflecteren.

De zorgstage kent algemene leerdoelen (bijvoorbeeld 'privacy respecteren', 'hygiënisch werken') en persoonlijke leerdoelen. Omdat de persoonlijke leerdoelen direct na een korte oriëntatiefase en vóór het eerste gebruik van het portfolio worden opgesteld, betreffen ze de taakuitvoering en de omgang met anderen en zichzelf, en niet de vaardigheid om te reflecteren. Bij ieder reflectieverslag komen de studenten zowel op de persoonlijke leerdoelen als op de algemene leerdoelen van de stage terug (zie figuur 1).

In navolging van de aanbevelingen van de werkgroep Consilium Abeundi ${ }^{3}$ is er in het Leidse curriculum voorzien in een longitudinale beoordeling van professioneel gedrag. Zo worden de studenten in de jaren 2, 3 en 4 in hun omgang met simulatiepatiënten en elkaar beoordeeld middels directe observatie, terwijl in jaar 1 het leren reflecteren centraal staat. Deze lijn in het curriculum is gebaseerd op de aanname dat het kunnen reflecteren voorwaardelijk is voor de verdere ontwikkeling van het professionele gedrag. ${ }^{4}$

Beoordeling op basis van een portfolio waarin zo zwaar het accent ligt op reflectie is niet vrij van problemen. Voorkomen dient te worden dat de studenten zich geremd voelen te reflecteren, omdat zij weten dat zij beoordeeld zullen worden. ${ }^{5-6}$ De combinatie van leren reflecteren en beoordelen wringt bij dit portfolio des te meer omdat studenten worden aangemoedigd te reflecteren op hun gevoelens en emoties. Dus ook als zij negatieve gevoelens ten aanzien van patiënten heb-

\section{Portfolio-opdracht: Helpen bij zich verplaatsen en toiletbezoek}

Van de algemene leerdoelen (blz. 10) ga ik letten op (bijv. de patiënt tot steun zijn, privacy respecteren, handig worden met verplaatsen, hygiënisch werken):

Van mijn persoonlijke leerdoelen (blz. 58) ga ik letten op:

Ik heb het volgende geleerd:
Ik wil nog verder verbeteren: (mijn zwakke punten/ geef voorbeelden):

Aanvankelijk had ik tijdens het verplaatsen/toiletbezoek de volgende gevoelens (geef voorbeelden):

Inmiddels zijn mijn gevoelens tijdens het verplaatsen/toiletbezoek als volgt veranderd (geef voorbeelden):

Figuur 1. Voorbeeld van een reflectieopdracht uit het portfolio. 
ben, zouden zij hun reflecties aan het portfolio moeten kunnen toevertrouwen zonder dat zij het risico lopen, afgerekend te worden op het feit dat zij negatieve gevoelens hebben. Om beoordeling bij het zorgstageportfolio toch mogelijk te maken zonder dat daarmee de kwaliteit van de reflectie onder druk komt te staan, zijn de volgende condities gecreëerd. Ten eerste is ervoor gekozen de student eigenaar te laten zijn van het portfolio. Alleen de student schrijft erin en het portfolio wordt na afloop van de stage niet ingeleverd.6-7 Ten tweede is ervoor gekozen om het portfolio de status te geven van een inspanningscontract: iedere reflectieopdracht wordt afgetekend als:

- de student heeft geprobeerd de (zorg) taak te verrichten volgens de instructie;

- de student heeft gereflecteerd op de uitvoering van de taak en/of gedrag en/of communicatie;

- de student heeft gereflecteerd op zijn/ haar gevoel.

Criterium bij de beoordeling is dat er wordt gereflecteerd en dat de onderwerpen van deze reflectie afwisselend taakuitvoering, omgang met anderen en omgang met zichzelf betreffen. Eventuele, geuite negatieve gevoelens (bijvoorbeeld ten aanzien van patiënten) zijn geen reden om een student een onvoldoende beoordeling te geven, maar geven vanzelfsprekend wel aanleiding tot een gesprek met de begeleider.

\section{Onderzoeksvragen}

Door per portfolio-opdracht aandachtspunten te geven (zie figuur 1) probeerden wij de studenten reflectie te leren. ${ }^{5-6} \mathrm{Bij}$ het lezen van de portfolioverslagen viel ons echter de variatie in uitwerkingen op. Daar waar de ene student een feitelijke beschrijving geeft van wat zij geleerd heeft, probeert de andere student te achterhalen waarom zaken goed of minder goed zijn verlopen. Vergelijk: Student X:
"Voor het wassen eerst alle kleding uitzoeken, handdoek, washandjes en wasemmertje gevuld met zeep. Dan eerst het gezicht wassen en drogen (...)." Student Y: "Bij toiletbezoek geduld opbrengen, omdat het eigenlijk een heel vernederende situatie is. Ik heb geleerd om telkens na te denken hoe ik me zou voelen als er iemand bij stond, bij het toiletbezoek."

Wij kwamen gaandeweg tot de ontdekking dat we zelf tamelijk vage ideeën hadden over wat kwalitatief goede reflectie is, en dat we in de portfolio-opdrachten het eigenlijk geheel aan de studenten overlieten hoe zij precies reflecteren. Daarom besloten wij dat het zinvol was om een scherpere definitie te ontwikkelen van reflectie: wat zien wij als gewenste soorten reflectie? Daarnaast wilden wij een helder beeld krijgen van wat studenten nu precies doen als zij reflecteren: hanteren de studenten de gewenste soorten reflectie en worden die soorten reflectie ook door beoordelaars herkend? Omdat de ontwikkeling van professioneel gedrag zo'n prominente plaats in de stage inneemt, waren wij tenslotte ook nieuwsgierig of de reflecties van de studenten op de drie domeinen (taakuitvoering, omgang met anderen en omgang met zichzelf) betrekking hadden. Omdat studenten dikwijls niet uit zichzelf reflecteren op onderwerpen die hen niet zo vertrouwd zijn, ${ }^{5}$ leek het de moeite waard dit domeinenonderscheid te maken. Als de studenten bijvoorbeeld voornamelijk op de taakuitvoering en niet op omgang met anderen zouden reflecteren, dan zou het leerdoel 'ontwikkelen van professioneel gedrag' niet worden bereikt.

\section{Theoretische achtergrond}

Bij de ontwikkeling van de zorgstage zijn wij met Kolb en Gibbs ervan uitgegaan dat reflectie een zinvolle onderwijsactiviteit is die bijdraagt tot 'deep learning'8-9 
en aanzet tot zelfsturend vermogen. ${ }^{4}$ Wat we precies onder reflectie verstaan, was zoals eerder opgemerkt - echter niet kristalhelder. Terugblikken en overdenken fase 2 uit de cirkel van Kolb - vormen ons inziens de minimale elementen van reflectie, maar daarnaast zijn ook persoonlijke betrokkenheid (er wordt teruggeblikt op een eigen ervaring en niet uitsluitend op ervaringen van anderen), een zekere mate van bewustheid (tot uitdrukking komend in het opschrijven van de ervaringen) en doelgerichtheid (in de vorm van het formuleren van verbeterpunten) belangrijke elementen van reflectie. ${ }^{10}$

Een precieze omschrijving van wat goede en gevarieerde reflectie behelst, zodat studenten geleerd kan worden met voldoende diepgang te reflecteren, konden wij in de literatuur niet vinden. Kolb ${ }^{8}$ en Korthagen ${ }^{11}$ geven een beschrijving van de fasen van het reflectieproces: de ervaring beschrijven, conclusies trekken/ analyseren en vervolgens generalisaties testen bij nieuwe ervaringen. Een dergelijke beschrijving is te lezen als een instructie om reflectie te entameren, maar biedt geen handvat om bijvoorbeeld de diepgang van de reflectie te beschrijven.

Filosoferend over de aard van reflectie stelt Korthagen in een andere publicatie ${ }^{12}$ dat reflectie van studenten beïnvloed wordt door de doelen en vormgeving van het onderwijs. Dit uitgangspunt is volgens ons goed te gebruiken om te achterhalen welke soorten reflectie wij wenselijk vinden, al betekent dit niet dat wij daarmee onmiddellijk de soorten reflectie geoperationaliseerd hebben.

De aanpak van Mansvelder-Longaroux et al. ${ }^{13}$ biedt wel handvatten voor het operationaliseren van reflectie. Ook zij hebben de aard van reflectie -in hun geval van docenten-in-opleiding- onderzocht. Daarbij hebben zij zich laten leiden door de leeractiviteiten zoals die door Vermunt ${ }^{14}$ worden onderscheiden. Vermunt stelt dat de leeractiviteiten -zowel cognitieve als affectieve en metacognitieve- in belangrijke mate de kwaliteit van het geleerde bepalen. Mansvelder-Longaroux et al. hebben gekeken welke leeractiviteiten van Vermunt zij in de portfolioverslagen tegenkwamen en deze selectie (na eventuele herbenoeming en aanpassing) vervolgens gebruikt voor het categoriseren van de reflectie. Een dergelijke werkwijze leek ons een bruikbare operationalisatie om soorten reflectie te categoriseren, waarbij wij bovendien recht konden doen aan de opzet, leerdoelen en vormgeving van de stage en het portfolio, daarbij aansluitend bij Korthagen. ${ }^{12}$

\section{Methode}

\section{Materiaal}

Naast de vijf in de inleiding genoemde opdrachten die gericht zijn op het uitvoeren van handelingen (wassen, aankleden, etc.) is ook de samenvatting waarin de studenten de reflecties op de vijf opdrachten moeten samenbrengen, bestudeerd.

\section{Dataverzameling}

In het studiejaar 2000-2001 zijn 12 van de 180 beschikbare portfolio's at random geselecteerd. In 2001-2002 zijn nog eens 38 at random geselecteerde studenten (van de groep van 200 studenten) aangeschreven met het verzoek hun afgeronde portfolio in te leveren. De studenten konden hun portfolio anoniem insturen. Er kwamen op deze oproep 28 portfolio's retour. Door het grote aantal participerende verpleeghuizen lijkt met deze at-randomselectie spreiding over de diverse verpleeghuizen (en daarmee een voldoende spreiding over de begeleiders) gegarandeerd. De portfolio's zijn gekopieerd. Van de 28 portfolio's zijn er 2 buiten beschouwing gelaten vanwege de onleesbaarheid van het materiaal. 


\section{Data-analyse}

In navolging van Mansvelder-Longaroux et al. ${ }^{13}$ is ook onze lijst met reflectieactiviteiten tot stand gekomen via een iteratief proces. Vanuit de theorie (Kolb en Vermunt ${ }^{8,14}$ ) hebben wij een lijst gewenste reflectieactiviteiten opgesteld en deze vergeleken met de leerdoelen en de vormgeving van het portfolio ${ }^{12}$ en 20 portfolioverslagen (verspreid over de twee betrokken studiejaren). Na bijstelling van de lijst is deze opnieuw naast de leeractiviteiten van Vermunt gelegd om tot een definitieve versie te komen. Bij de bestudering van de portfolioverslagen bleek bovendien het professionele gedragsdomein 'omgang met anderen' en 'omgang met zichzelf' beter herkenbaar als we het omdoopten tot respectievelijk 'communicatie' en 'attitude en gevoel'.

De resterende 18 verslagen zijn door twee onderzoekers bestudeerd, waarbij er per opdracht genoteerd werd of gewenste soorten reflectie terug te vinden waren en of er op taakuitvoering, communicatie en attitude/gevoel werd gereflecteerd. Omdat wij een lijstje gewenste reflectieactiviteiten hebben opgesteld, waren wij geïnteresseerd of veel (liefst alle) studenten in staat waren in iedere opdracht deze soorten reflectie tentoon te spreiden. Onze teleenheid was dus een portfolio-opdracht (zes opdrachten per student). Deze aanpak wijkt af van bijvoorbeeld Mansvelder et al. ${ }^{13}$ en Wade en Yarbrough ${ }^{6}$ die de verslagen hebben gesegmenteerd en daarna het voorkomen van de soorten reflectie hebben geteld.

Omdat wij wilden weten hoe werkbaar dan wel betrouwbaar een onderscheid tussen de verschillende reflectieactiviteiten en de drie domeinen is, is met behulp van Cohens kappa ${ }^{15}$ de mate van overeenstemming tussen de onderzoekers bepaald. In een logboekje hebben de onderzoekers opvallende zaken genoteerd.

\section{Resultaten}

\section{Vijf reflectieactiviteiten}

De volgende lijst gewenste reflectieactiviteiten hebben wij uiteindelijk samengesteld:

- Selecteren en beschrijven van gedrag. Er wordt antwoord gegeven op de vraag: wat heb ik geleerd en/of gedaan? Hierbij is een uitsplitsing gemaakt naar de drie domeinen: 1) uitvoering van de taak; 2) communicatie met patiënten of collega's; en 3) attitude.

- Evalueren. De centrale vraag is: heb ik bereikt wat ik wilde bereiken? Ook hier is de uitsplitsing naar de verschillende domeinen gemaakt.

- Analyseren. De student onderzoekt: waarom is iets goed of fout gegaan, hoe komt het komt dat ik me heb ontwikkeld.

- Plannen. Wat zijn mijn verbeterpunten? Ook hier weer met de uitsplitsing naar domein.

- Generaliseren. Wat heb ik (over mezelf) geleerd dat ik ook in andere situaties kan gebruiken? Als de student nauwelijks relaties kan leggen tussen een specifieke ervaring en andere (verwante) ervaringen, dan zal hij/zij het nut van het bijhouden van een portfolio niet zo snel zien. ${ }^{4}$

Vervolgens hebben twee beoordelaars de 18 resterende portfolio's (108 opdrachten) gescoord op aanwezigheid van deze reflectieactiviteiten en domeinen.

\section{Herkenbaarheid van de domeinen}

Het onderscheid tussen de verschillende domeinen blijkt in de praktijk nauwelijks werkbaar. De twee onderzoekers verschilden erg van mening of een reflectie nu betrekking had op de taakuitvoering, de communicatie of de attitude. Zo waren ze het wel in hoge mate met elkaar eens dat de student zich een leerdoel stelde (een 
noodzakelijk onderdeel van de reflectieactiviteit 'evalueren') (kappa .884), maar verschilden zij van mening welk domein dit nu betrof (kappa's varieerden van .532 tot .669). Dit is niet helemaal onbegrijpelijk als men bijvoorbeeld het volgende leerdoel leest: "Goed verplaatsen in iemands situatie en inleven. Dan vragen stellen die passend zijn." Het leerdoel betreft de attitude van de student, maar staat ten dienste van een communicatief doel. Dat er een leerdoel wordt gesteld, is helder, maar op welk domein dit leerdoel ligt, is moeilijker te bepalen.

Ook bij 'selecteren en beschrijven van gedrag' hadden de onderzoekers moeite de verschillende domeinen te herkennen: de kappa's lopen daar uiteen van .335 tot .472. De twee onderzoekers zijn daarentegen wel redelijk eensgezind over het feit dat de student iets beschrijft wat hij/zij heeft geleerd (kappa 0.714). Ook dat is niet zo verwonderlijk getuige het volgende voorbeeld:"Bij het geven van eten heb ik geleerd hoe ik dit op een handige manier kon doen waardoor ik meer zelfstandigheid en zelfvertrouwen kreeg. Bovendien was het belangrijk dat ik de bewoners leerde kennen zodat ik (...) op de juiste manier met ze kon communiceren." We kunnen het er makkelijk over eens zijn dat deze student beschrijft wat hij/zij geleerd heeft, maar over het domein dat hij/zij beschrijft, kunnen we twisten. De taak lijkt centraal te staan, maar en passant worden een attitude- en een communicatieaspect meegenomen.

De spreiding over de drie domeinen van professioneel gedrag viel niet tegen. Wanneer er wordt geabstraheerd van de verdeling over de reflectieactiviteiten, dan zien we dat in $58 \%$ van de portfolio-opdrachten gereflecteerd wordt op taakuitvoering, in $49 \%$ van de opdrachten op attitude/ gevoel en in $40 \%$ van de opdrachten op communicatie.

\section{Herkenbaarheid van de vijf reflectie- activiteiten}

Bij de reflectieactiviteiten zien we een wisselende beoordelaarsovereenstemming (tabel 1).

De beoordelaarsovereenstemming bij 'analyseren en generaliseren' was het meest teleurstellend: kappa's bedroegen .15. Dat betekent dat de overeenstemming nog lager is dan de toevalskans voor overeenstemming. De ene onderzoeker is bij het scoren op de aanwezigheid van deze twee reflectieactiviteiten veel coulanter geweest dan de andere.

Maar zelfs bij de meest coulante beoordelaar komt nog maar in $37 \%$ van de portfolio-opdrachten de reflectieactiviteit analyseren' voor. Bovendien analyseren de studenten niet met bijzonder veel diepgang, getuige de logboekjes. Meestal wordt gewenning aangevoerd als motivatie van een ontwikkeling: "In het begin een gênant gevoel. Een ouder iemand eten geven. Gevoel van onhandigheid. Mijn gevoelens zijn veranderd. Ik zag dat patiënt het lekker vond en ik merkte dat ik helemaal niet zo onhandig was." Wanneer er een andere verklaring dan gewenning wordt aangedragen, valt het op dat bewust actie is ondernomen om iets te leren: "Ik ben zelf in een rolstoel gaan zitten en heb me laten rondrijden door iemand. Het is heel beangstigend als je niet weet waar je heen gaat. Het is daarom belang-

Tabel 1. Beoordelaarsovereenstemming op de verschillende reflectieactiviteiten.

\begin{tabular}{lc}
\hline Reflectieactiviteit & Kappa \\
\hline Selecteren en beschrijven van gedrag & .714 \\
Evalueren & .468 \\
Analyseren & .151 \\
Plannen & .624 \\
Generaliseren & .152 \\
& \\
Gevoel & .384 \\
\hline
\end{tabular}


Tabel 2. Aantal keren (absoluut en percentueel) dat analyseren en generaliseren in de portfolio's voorkwamen. $(n=108)$.

\begin{tabular}{lcc}
\hline & Analyseren & Generaliseren \\
\hline Beoordelaar 1 & $40(37 \%)$ & $45(42 \%)$ \\
Beoordelaar 2 & $23(21 \%)$ & $20(18 \%)$ \\
\hline
\end{tabular}

Tabel 3. Aantal keren (absoluut en percentueel) dat de reflectie-activiteiten voorkomen ( $n=108)$.

\begin{tabular}{lc}
\hline Selecteren en beschrijven & $104(96 \%)^{*}$ \\
Evalueren & $88(81 \%)$ \\
Plannen & $82(76 \%)$ \\
\hline * Getallen uitgaande van wat de minst coulante onderzoeker aan- \\
trof.
\end{tabular}

rijk niet te hard te rijden met een rolstoel en links en rechts aan te geven."

Voor de reflectieactiviteit 'generaliseren' is het niet veel anders. Zelfs de meest coulante onderzoeker geeft aan dat deze reflectieactiviteit weinig terug te vinden is in de portfolio-opdrachten (tabel 2). De onderzoekers melden in de logboekjes dat juist bij generaliseren sprake lijkt te zijn van een belangrijk leermoment:

Student X: "Bij het voeren van mensen denk ik dat ik me wat betuttelend heb opgesteld. (...) Het was niet de bedoeling me betuttelend op te stellen, maar als je de enige bent die praat, weet je vaak niet goed waar je het over moet hebben. Een lange stilte hoeft niet verkeerd te zijn."

De reflectieactiviteiten 'selecteren en beschrijven' en 'plannen' werden niet alleen beter herkend in de producten (gezien de relatief hoge kappa's in tabel 1), zij kwamen ook veel vaker voor (zie tabel 3). 'Evalueren' komt vaak voor, maar de beoordelaarsovereenstemming is weer lager dan bij selecteren en beschrijven en plannen.

\section{Conclusies en discussie}

Onze zoektocht naar een scherpere definitie van reflectie ten behoeve van de vormgeving van de zorgstage heeft een lijstje met reflectieactiviteiten opgeleverd, bestaande uit 'selecteren en beschrijven', 'evalueren', 'analyseren', 'plannen' en 'generaliseren'. Het zijn de soorten reflectie die wij op basis van literatuurstudie, de vormgeving van de stage en bestudering van de portfolioverslagen wenselijk achten.

Verder wilden wij een helder beeld krijgen van wat studenten nu precies doen als zij reflecteren: hanteren de studenten de gewenste soorten reflectie en kunnen de beoordelaars deze soorten reflectie herkennen? Voor de reflectieactiviteiten 'selecteren en beschrijven' en 'plannen' kan gesteld worden dat zij goed kunnen worden herkend door de onderzoekers en dat studenten deze reflectieactiviteiten vaak uitvoeren. Dat 'plannen' vaak voorkomt, is niet zo heel verwonderlijk: zoals in de inleiding (figuur 1) duidelijk is gemaakt, worden de studenten hier direct op aangestuurd.

'Evalueren' komt volgens de onderzoekers vaak voor - ondanks dat het portfolio de studenten hier weinig toe aanzet (zie weer figuur 1) -, maar de onderzoekers zijn minder eensgezind over of een reflectie nu evaluatief is of niet. Bij 'evalueren' kan het onderscheid tussen de drie domeinen van professioneel gedrag mogelijk tot de wat lagere beoordelaarsovereenstemming hebben geleid: Leerdoel: "Zo flexibel mogelijk communiceren met de bewoner. Het eten geven zal dan makkelijker worden. Beschrijving: "Accepteren ze het (d.i. het eten geven) niet, dan kun je beter niet dwingen. Vraag dan of ze nog een toetje willen (dan eten ze tenminste nog iets)." De student heeft zich een communicatieleerdoel gesteld, maar het is 
niet helemaal duidelijk of hij/zij hier op terugkomt. Het inzicht dat je mensen beter niet kunt dwingen iets te doen, heeft ook een attitudecomponent. De ene onderzoeker vindt dat de student wel terugkomt op zijn/haar communicatieleerdoel, de andere vindt van niet.

‘Analyseren en generaliseren' blijken niet alleen weinig voor te komen, de beoordelaars verschillen ook van mening of ze voorkomen. In tegenstelling tot bij 'evalueren' speelt bij deze reflectieactiviteiten niet het probleem van uitsplitsing naar de drie domeinen van professioneel gedrag (er was geen uitsplitsing). Omdat de beoordelaars (zeer) goed waren ingevoerd in het herkennen van de reflectieactiviteiten, lijkt een betere training niet een doeltreffende oplossing voor dit probleem.

Wat we wel zien, is dat het portfolio geen sturing (zie figuur 1) bevat die studenten aanzet tot dit soort reflectieactiviteiten, en we zien (in tegenstelling tot 'evalueren') dat studenten deze reflectieactiviteiten niet spontaan verrichten. Driessen et al. ${ }^{5}$ wijzen erop dat reflectie via vragen kan worden gestimuleerd, waarbij het voor de ontwikkelaar van het portfolio soms lastig is het evenwicht te vinden tussen niet al te sturend zijn (en daarmee genoeg ruimte aan de student overlatend), maar nog wel sturend genoeg. Het stellen van de waarom-vraag (analyseren) wordt als een belangrijke motor voor ontwikkeling gezien: de instructies voor reflectie van Kolb en Korthagen zijn er grotendeels op gebaseerd. Ook 'generaliseren' is een belangrijke reflectieactiviteit, waarvoor aansturing in het portfolio ontbreekt. Door te generaliseren wordt het geleerde immers toepasbaar in nieuwe situaties en daarmee is deze reflectieactiviteit noodzakelijk om bij de studenten bereidheid te creëren om tijd te steken in reflecteren.5,15
Juist omdat 'analyseren' en 'generaliseren' belangrijke reflectieactiviteiten zijn, zouden deze ook beoordeeld moeten worden als wij uitgaan van het adagium 'testing drives learning'. Dat betekent op de eerste plaats dat studenten in het portfolio moeten worden aangezet tot deze reflectieactiviteiten; ze doen deze reflectieactiviteiten immers niet spontaan. Eerdere studies ${ }^{17}$ tonen weliswaar niet altijd een enorme verhoging van de beoordelaarsovereenstemming aan wanneer de structuur van het portfolio helderder wordt gemaakt, maar deze resultaten zijn niet zonder meer te generaliseren naar ons portfolio dat immers weer anders is vormgegeven. Het zou zo kunnen zijn dat beoordelaars het meer met elkaar eens zijn als ze generaliserende reflecties lezen onder een kopje als: "Je hebt aangegeven een aantal dingen te hebben geleerd. Wat ga je daarvan gebruiken in volgende situaties?"

Passend bij de leerdoelen van de zorgstage was een uitsplitsing van de reflecties van studenten naar de drie domeinen van professioneel gedrag, te weten taakuitvoering, omgang met anderen (communicatie) en omgang met zichzelf (attitude/gevoel). ${ }^{1}$

De studenten lijken niet zeer eenzijdig te reflecteren door bijvoorbeeld uitsluitend op de taakuitvoering in te gaan. Zij reflecteren ook op attitude/gevoel en daar worden zij ook op aangestuurd (zie figuur 1). Met opzet spreken wij van 'lijken', omdat de gegevens over de spreiding van de reflecties op de drie domeinen met voorzichtigheid gehanteerd moeten worden: de domeinen zijn voor de onderzoekers niet eenduidig te herkennen. Dat is voor de uitvoering van de reflectietaak en de aansturing van studenten wellicht niet zo erg. Er wordt veelal gereflecteerd op competenties waarbij communicatie, attitude, gevoel en 
het uitvoeren van de taken vervlochten zijn: een goede communicatie helpt een adequate uitvoering van de taak, waardoor weer een gevoel van zekerheid ontstaat. Voor beoordeling lijkt het echter niet verstandig de domeinen te onderscheiden.

De betrouwbaarheid van portfoliobeoordelingen blijft ook bij het portfolio voor de zorgstage een punt van zorg. Oplossingen die elders worden bedacht ${ }^{18}$ zijn niet zonder meer te gebruiken in onze situatie, met name omdat wij één aspect van het portfolio (de reflectie) willen beoordelen. Reflectie is een belangrijk element van portfoliobeoordelingen bij veel opleidingen. Daarom lijkt het verstandig meer energie te steken in het verhogen van de betrouwbaarheid van de kwaliteit van de reflectie. In een vervolgstudie waarin de reflecties van studenten worden gevolgd wanneer zij daar expliciet op zijn aangestuurd, zal bekeken worden in hoeverre studenten dan wel in staat zijn alle gewenste reflectieactiviteiten uit te voeren en of de beoordelaarsovereenstemming eveneens verbetert. Ook het codeerschema zal nog gepreciseerd worden, waarbij niet alleen omschrijvingen van de reflectieactiviteiten worden gegeven, maar ook een aantal voorbeelden.

Tot slot nog iets over de rol van de begeleiders. De studenten hebben tijdens de zorgstage verschillende soorten begeleiders: verzorgenden, hoofden opleiding, verpleeghuisartsen. Zij allen ondersteunen de student bij de reflectietaken en zullen dat ieder op een eigen manier doen. Door hun diversiteit zal juist de (enorme) groep begeleiders baat hebben bij een heldere structuur van het portfolio, waarbij voor studenten en begeleiders helder is welke soorten reflectie er verwacht worden. Het domein waarop de student reflecteert (taakuitvoering, communicatie, attitude/gevoel) kan hij/zij dan samen met de begeleider kiezen.

\section{Literatuur}

1. Luijk SJ van, Santen-Hoeufft M van, Schrander J. Relevante ervaringen met onderwijs en toetsing van professioneel gedrag. Tijdschrift Medisch Onderwijs 2003;22(3):128-38.

2. Wolf K, Dietz M. Teaching portfolio's: purposes en possibilities. Teaching Education Quaterly; 1998.

3. Werkgroep Consilium Abeundi van het DMW (VSNU). Beoordeling van de algemene klinische competentie. Utrecht: VSNU; 2000.

4. Boekaerts M, Simons PR. Leren en instructie. Psychologie van de leerling en het leerproces. Assen: Dekker \& Van de Vegt; 1993.

5. Driessen EW, Tartwijk J van, Vermunt JD, Vleuten CPM van der. Use of portfolios in early undergraduate medical training. Med Teach 2003;25:18-23.

6. Wade RC, Yarbrough DB. Portfolio's: a tool for reflective thinking in teacher education. Teaching \& Teacher Education 1996;12:63-79.

7. Snadden D, Thomas M. The use of portfolio learning in medical education. Med Teach 1998;20: 192-9.

8. Kolb D. Experimental learning. Chicago: Prentice Hall; 1984.

9. Gibbs G. Improving the quality of student learning. Bristol: Technical and Education Services; 1992.

10. Vos H, Vlas H. Reflectie en actie [interne publicatie]. Van Dinkelinstituut; 2000.

11. Korthagen F. Leren reflecteren: naar systematiek in het leren van je werk als docent. In: FonderieTierie L, Hendriksen J, editors. Begeleiden van docenten. Baarn: Nelissen; 1998. p. 43-6.

12. Korthagen FA. Linking practice and theory: the pedagogy of realistic teacher education. Mahwah, NJ: Lawrence Erlbaum Associates, Inc.: 2001.

13. Mansvelder-Longaroux D, Beijaard D, Verloop N. Het portfolio als reflectie-instrument voor docenten-in-opleiding. Pedagogische Studiën 2002;4: 69-86.

14. Vermunt J. Leerstijlen en sturen van leerprocessen in het hoger onderwijs. Naar procesgerichte instructie in zelfstandig denken. Lisse: Swets \& Zeitlinger; 1992.

15. Eggers, TJHM, Sanders PF. Psychometrie in de praktijk. Arnhem: Cito; 1993.

16. Snadden D, Thomas M, Challis M. AMEE: Educational Guides. 1999:11. Portfolio-based learning and assessment in medical education.

17. Pitts J, Coles C, Thomas P. Enhancing reliability in portfolio assessment; 'shaping' the portfolio. Med Teach 2001;23:351-6.

18. Straetmans GJJM. Protocol portfolio scoring. Onderwijsinnovatie 2004; juni 2004. 
De auteurs:

Mw. drs. S. Vink is als onderwijskundig adviseur verbonden aan het ICLON van de Universiteit Leiden.

Prof. dr. H.J.M. Cools is hoogleraar verpleeghuisgeneeskunde, LUMC, Universiteit Leiden.

Drs. GMF Elsen is als onderwijskundig adviseur verbonden aan het ICLON van de Universiteit Leiden.

Dr. J.D. Vermunt is als universitair hoofddocent verbonden aan het ICLON van de Universiteit Leiden.
Correspondentieadres:

Mw. drs. S. Vink, ICLON, Postbus 9555, 2300 RB

Leiden, tel.: 071-5274059,svink@ICLON.leidenuniv.nl.

\section{Summary}

Introduction: Students at Leiden medical school are encouraged to include in their portfolios reflections on a period of practical work experience in Year 1. We sought to answer the following questions: which types of reflection are appropriate for this module and which of these types were demonstrated by students? Did students reflect on different domains of professional behaviour? Was it possible to identify the different types of reflection and reflections on different domains of professional behaviour?

Method: We consulted the literature and twenty portfolios in developing a list of reflection types and domains of professional behaviour that were suitable for reflection. Two researchers categorised 108 reflections and counted the number of reflections for each type. Inter-rater agreement was determined using Cohen's kappa.

Results: The types of reflection were: (a) selection and description, (b) evaluation, (c) analysis, (d) planning and (e) generalisation. Analysis and generalisation were rarely encountered. Inter-rater agreement was poor and disagreements on classification by domains of professional behaviour were frequent. For planning and selection/description interrater agreement was good, however. Evaluation occurred frequently. Reflections were found on all three domains of professional behaviour (task, communication, attitudelemotions).

Conclusions and discussion: It proved difficult to identify the different types of reflection. The frequency of the different types of reflection was low, except for evaluation. This suggest that students should be better informed about the types of reflection they are expected to demonstrate. The different domains of professional behaviour turned out to be difficult to identify. Inter-rater reliability must improve before any firm conclusions can be drawn from students' reflections. (Vink S, Cools HJM, Elsen GMF, Vermunt JD. The reflections of first year undergraduate medical students. Dutch Journal of Medical Education 2005;24(1):4-13.) 